\title{
Rubinstein-Taybi syndrome
}

In this review a short overview of pertinent clinical and molecular data of the Rubinstein-Taybi syndrome are provided. A diagnostic decision algorithm, and major issues that should be considered in the management of patients are discussed. Suggestions for further research are given.

\section{In brief}

- Incidence of 1:100000-125000 at birth.

- The diagnosis RSTS is still essentially a clinical diagnosis.

- A cytogenetic or molecular abnormality can be detected in 55\% of RSTS patients.

- RSTS can be caused by mutations in either CBP or p300.

- Isolated loss of histone acetyl transferase (HAT) activity of CBP can cause RSTS.

- The empirical recurrence risk after an earlier child with RSTS is $0.1 \%$.

- Management strategies are symptomatic.

- RSTS patients have an increased tumor risk but surveillance is not well possible.

- RSTS patients can develop behavior problems in adulthood which pleas for a postnatal disfunctioning of $\mathrm{CBP} / \mathrm{p} 300$.

Raoul CM Hennekam*,1,2

${ }^{1}$ Clinical and Molecular Genetics Unit, Institute of Child Health, Great Ormond Street Hospital for Children, UCL, London, UK; ${ }^{2}$ Department of Paediatrics, AMC, University of Amsterdam, Amsterdam, The Netherlands

European Journal of Human Genetics (2006) 14, 981-985.

doi:10.1038/sj.ejhg.5201594; published online 26 July 2006

Keywords: Rubinstein-Taybi syndrome; CBP; p300; diagnostic algorithm; management

*Correspondence: Dr RCM Hennekam, Clinical and Molecular Genetics Unit, Institute of Child Health, Great Ormond Street Hospital for Children, UCL, 30 Guilford Street, London WC1N 1 EH, UK.

Tel: + 44207905 2608; Fax: + 44207905 2832;

E-mail: r.hennekam@ich.ucl.ac.uk

Received 22 November 2005; revised 21 December 2005; accepted 23 December 2005; published online 26 July 2006

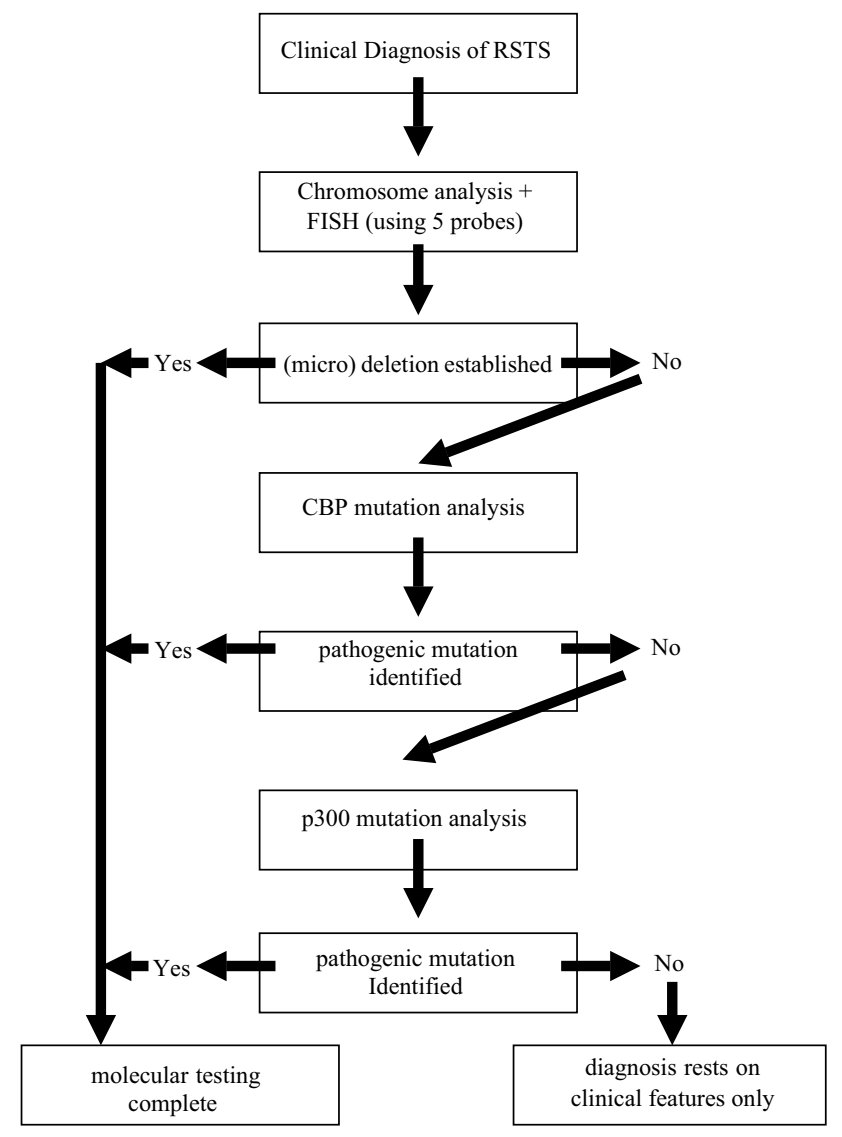

Figure 1 Diagnostic strategy for RSTS. A microdeletion at \#16p13.3 or a mutation in CBP/p300 can be found in about 55\%, leaving the diagnosis in $45 \%$ of the patients to rest on clinical features only.

\section{Introduction}

The Rubinstein-Taybi syndrome (RSTS; OMIM 180849) is a well-defined multiple congenital anomalies - mental retardation syndrome characterized by postnatal growth deficiency, microcephaly, specific facial characteristics, broad thumbs and big toes, and mental retardation. ${ }^{1}$ It 
occurs generally sporadic, and can be caused by a microdeletion of chromosome 16p13.3, or by a mutation in either CREB-binding protein $(C B P)$ or E1A-binding protein ( $p 300)$. Birth prevalence is one in 100000-125000 (Figure 1). ${ }^{2}$

\section{Clinical overview}

The main features that allow for diagnosing RSTS are to be found at the face and limbs. The facial appearance is striking: highly arched eyebrows, long eyelashes, downslanting palpebral fissures, broad nasal bridge, beaked nose with the nasal septum extending well below the alae, highly arched palate, and mild micrognathia (Figure 2a and b). ${ }^{3}$ Of importance, is their facial expression: the grimacing or at least unusual smile with almost closing of the eyes is almost universally present. The finding of talon cusps at the permanent incisors can be helpful, as these are only rarely found in other entities (Figure 2c). ${ }^{4}$ Broad thumbs and broad big toes are present in almost all cases (Figure 3). Sometimes partial duplication of the first ray is present on either hands or feet, but truly preaxial polydactyly has never been described in a confirmed case. Thumbs and halluces are radially deviated in about $1 / 3$ rd of patients. In addition, terminal broadening of the phalanges of the fingers, persistent fetal pads, and clinodactyly of the fifth finger can be present. There is a marked growth retardation with poor weight gain during infancy, often replaced by overweight in later childhood
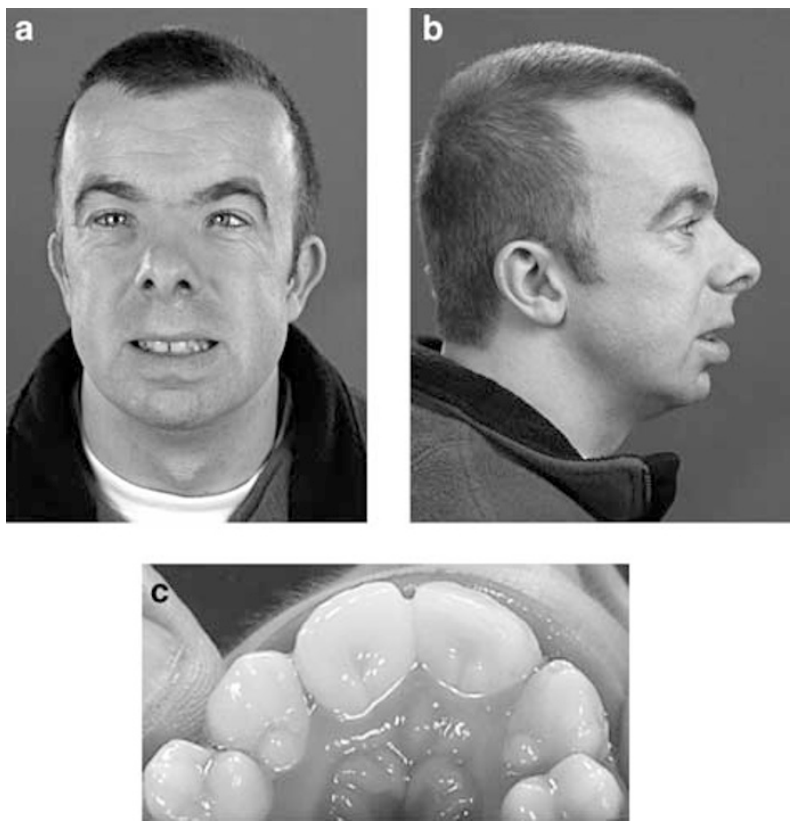

Figure 2 (a, b) Face in RSTS. Note classical features in molecularly proven patient. (c) Talon cusps in RSTS. The presence of talon cusps is a strong indicator that the diagnosis RSTS in a patient with only partial features of RSTS is right. or puberty. ${ }^{5}$ Other physical findings may include eye anomalies (nasolacrimal duct obstruction, ptosis of eyelids, congenital or juvenile glaucoma, and refractive errors), a variety of congenital heart defects, joint hypermobility, and skin anomalies (hirsutism, naevus flammeus on the forehead, and keloid formation). ${ }^{6,7}$ Global mental retardation is characteristic with an average IQ between 35 and 50, but a cognitive functioning outside these limits does occur. ${ }^{8}$ Although the cognitive delay is usually expressed, they have a marked ability to establish excellent social contacts. Their behavior is otherwise characterized by short attention span and poor coordination, and in early adulthood sudden mood changes occur, which seem to
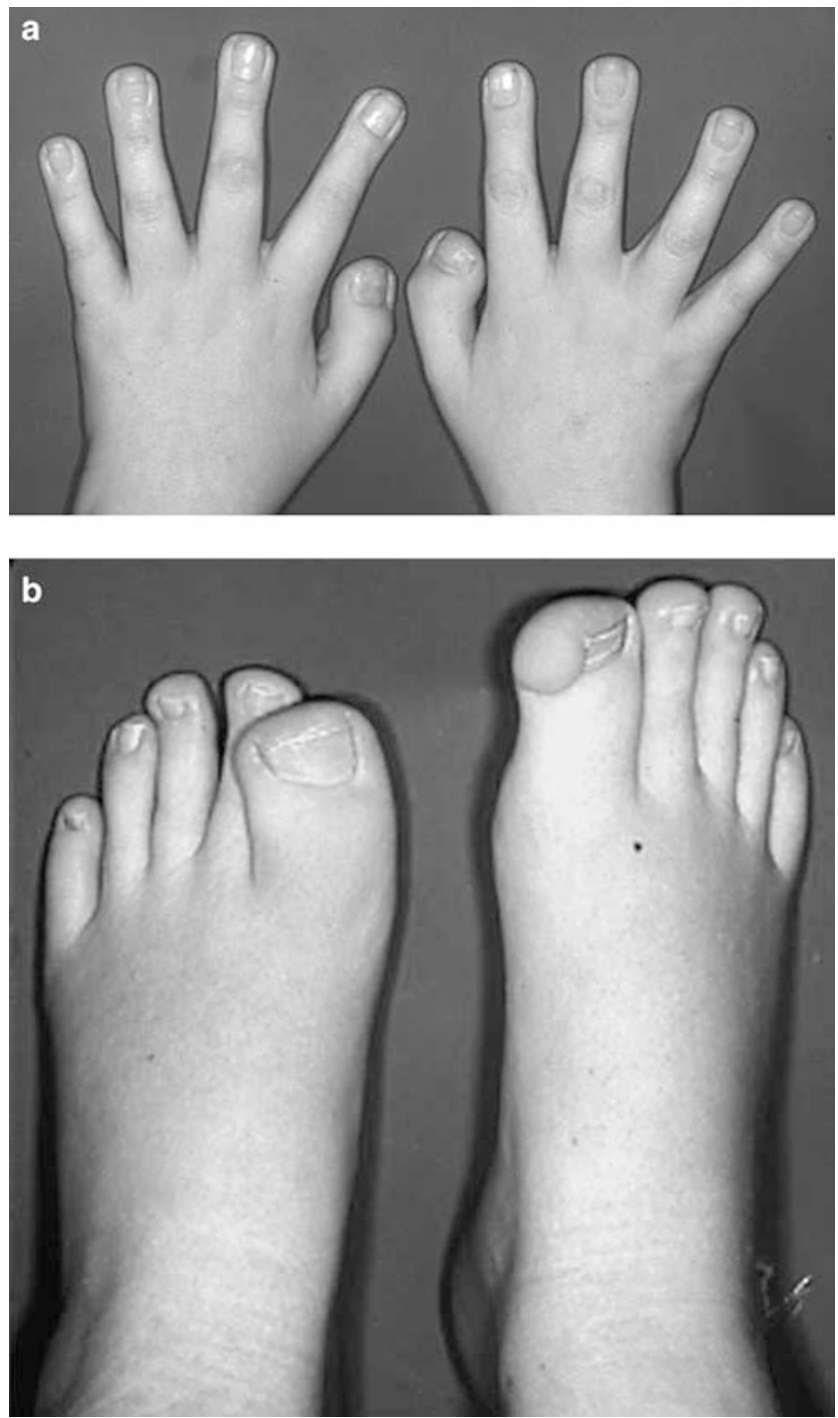

Figure 3 (a, b) Hands and feet in RSTS. Broad thumbs, broadened terminal phalanges, mild cutaneous syndactyly between third and fourth finger on the right, and broad halluces. Note variability of abnormalities of the first ray within a single patient. 
Table 1 Major clinical problems in Rubinstein-Taybi syndrome (adapted from 3 )

\begin{tabular}{lc}
\hline Feature & Percentage \\
\hline Polyhydramnios & 30 \\
Neonatal respiratory problems & 51 \\
Neonatal feeding problems & 80 \\
Tear duct obstruction & 39 \\
Strabismus & 58 \\
Refractive error & 41 \\
Upper airway infections & 60 \\
Hearing loss & 24 \\
Congenital heart defects & \\
Keloid formation & 32 \\
Malignancies & 25 \\
Seizures & $5 ?^{\mathrm{b}}$ \\
Growth retardation $<3$ rd centile & 23 \\
\hline
\end{tabular}

aMainly PDA, VSD, and ASD.

$\mathrm{b}$ In 74 Dutch patients four developed a malignancy.

increase with age. The clinical history often mentions feeding problems in the neonatal period, respiratory problems in the first decade, and life-long constipation. There is an increased risk to develop tumors, mainly meningeoma and other brain tumors, and leukemia. ${ }^{9}$ They tend to occur before 15 years of age, although meningeoma also occur in adulthood. Life expectancy seems to be normal. An inventory of the major medical problems in patients RSTS and their frequency are given in Table 1.

There are no diagnostic criteria for RSTS.

\section{Diagnostic approaches}

The approach is as in almost any entity: careful early history taking, family history, and physical examination are the cornerstones. The diagnosis is still essentially a clinical diagnosis, and rests on recognition of the characteristic features. In RSTS the major items to look for are the beaked nose with low hanging septum, grimacing smile, broad thumbs and big toes, and mental retardation. Dental inspection for the presence of talon cusps can be very useful, and to same holds to a lesser extend for the presence of larger keloids on the upper thorax and arms. One should be careful before one accepts the diagnosis in a child that has a normal growth.

Additional studies may include radiographies of hands and feet to check for (partial) duplications of the first rays. Checking for a microdeletion at chromosome $16 \mathrm{p} 13.3$ using a series of five probes (RT100, RT102, RT191, RT203, and RT166) and molecular analysis for mutations in $C B P$ and $p 300$ are helpful when an abnormality will be found. However, as in total by cytogenetic and molecular studies an abnormality can be detected in $55 \%$ of cases only, a negative result does not exclude the diagnosis.

A recommended diagnostic strategy is shown in Figure 1.

\section{Molecular and genetic basis}

Chromosome location at $16 \mathrm{p} 13.3$

Until 1991 many patients were cytogenetic anomalies were reported, but the chromosome rearrangements had been inconsistent with regard to their breakpoints. ${ }^{2}$ In that year and the year thereafter, three patients were reported with a cytogenetic anomaly all involving chromosome band 16p13.3. ${ }^{10-12}$ This urged a Dutch group to analyzed RSTS patients with FISH using the N2 and RT1 probes, and the detection of absence of one RT1 signal on chromosome 16 in six of 24 patients. ${ }^{13}$ UniParental Disomy of chromosome 16 was not found. ${ }^{14}$ Later studies showed this to be unusually high: in a review of the cytogenetic results of a total of 454 RSTS patients, 41 patients with a microdeletion were found. ${ }^{15}$ Clinical features are essentially the same in patients with or without detectable deletions, making it unlikely that RSTS is a contiguous gene syndrome. ${ }^{14}$

\section{Cloning the CBP gene}

The same group of Dutch investigators showed conservation of a subclone of RT1 with DNA from several species (zoo-blot). When used to screen a human fetal brain cDNA library a cDNA clone was found that contained an open reading frame of $573 \mathrm{bp}$. This open reading frame was found to show 92\% DNA homology with the murine Cbp. As all known deletions at those days (ranging from 50 to $>650 \mathrm{~kb}$ ) affected at least some part of the CBP gene, CBP was an excellent candidate gene for RSTS, and mutations were found. Since then all types of mutations have been found in RSTS patients, including intragenic duplications. Recent larger series have shown that mutations were detectable in 63 of 155 patients (41\%). ${ }^{15-18}$ The Human Gene Mutation Database (www.hgmd.org) holds at present 92 different mutations in the CBP gene - 13 missense substitutions, 20 nonsense substitutions, 10 splicing substitutions, 16 small deletions, nine small insertions, two small indels, 19 gross deletions, one gross insertion and two complex rearrangements.

\section{Genetic heterogeneity: p300}

It was already long known that $C B P$ has a homolog $p 300$ located at 22q13.2. They are not only highly related in primary structure ${ }^{19}$ but also in function. Especially both have a histone acetyl transferase (HAT) activity and function as a transcription co-activator. ${ }^{20}$ It was known that only the loss of the HAT activity of $C B P$ was sufficient to cause RSTS, ${ }^{16}$ although conflicting evidence has been published. ${ }^{17}$ The similarity between $C B P$ and $p 300$ urged the Dutch group to search for p300 mutations in RTST patients. Until now three patients have been detected, two with a mutation that causes loss of the HAT function of p300, one lead to absence of expression of the allele. ${ }^{18}$ The exact frequency of mutations of p300 in RTST is as yet unknown. The small number of patients known with a p300 mutation prevents comparing the phenotypes of $C B P$ 
and p300 RSTS patients; no obvious difference has been observed thus far.

At present, the cause of RSTS remains hidden in about half of the patients. In part, the detection rate may increase using recent advances in techniques such as denaturing high-performance liquid chromatography. Other mechanisms that could lead to reduced $C B P$ or $p 300$ production, such as promoter mutations, mutations within a possible locus control region, or mutations leading to defective protein processing, would also be possible pathogenic mechanisms for RSTS. Furthermore, both $C B P$ and $p 300$ interact with several co-factors (p/CAF; CITED1; CITED4), which can be involved in RSTS as well, and would indicate further genetic heterogeneity.

\section{Management}

\section{Genetic counseling}

Adequate counseling of parents of a child with RSTS involves first of all providing carefully formulated information on the syndrome itself. Parents want to provide optimal guidance and care to their child. In several countries, excellent written information for lay persons is available. Next, information regarding recurrence risks and prenatal diagnosis will be asked. RSTS is almost always a de novo occurring autosomal dominant entity. Proper cytogenetic investigations including FISH studies should be initiated followed by proper molecular studies if needed. The empiric recurrence risk for a couple with a previous child with RTS is as low as $0.1 \%{ }^{2}$ Molecularly confirmed germ line mosaicism has not been reported at present.

Persons who have RSTS can reproduce. In them, the recurrence risk could be as high as $50 \%$. As some adolescents and adults with RSTS are sexually active, males as well as females, this is an issue that must be addressed. If a cytogenetic or molecular abnormality has been detected, reliable prenatal diagnosis is possible.

\section{Treatment and care}

An early diagnosis of RSTS is critical, both for adequate information and for treatment of medical problems. In the first year of life, specific attention will be paid to the feeding problems, constipation, and lacrimal duct stenosis. All patients should be evaluated in the first months for congenital heart defects and for glaucoma. In males undescended testes can be surgically corrected if needed. If surgery or anesthetics are required, caregivers should be aware that RSTS patients are susceptible to tracheal collapse after muscle relaxating medications, which may cause intubation problems. In rare cases, patients have been hypersensitive to anesthetic agents. Later in life, the constipation should not be ignored, and weight gain resembling Prader-Willi syndrome can occur around puberty. The combination of a narrow palate, micrognathia, hypotonia, obesity, and easy collapsibility of the laryngeal walls has given rise to extreme snoring and obstructive sleep apneas. Refractive errors are common, hearing loss is less common and frequently caused by upper respiratory tract infections. The abnormal talon cusp shape of teeth causes an increased risk for caries. A small group of patients experience an increased fracture frequency, and many patients have joint hypermobility and lax ligaments that cause various orthopedic problems. Recently, attention was drawn to the occurrence of cervical vertebral anomalies. ${ }^{21}$ However, although such anomalies are not rare in RSTS, symptoms caused by the vertebral anomalies are extremely infrequent in the opinion of this author. It is suggested to perform radiological studies only if clinical symptoms (gait, reflexes, bladder, and bowel function) are present. Patients can have a tendency to develop keloids on upper chest and arms, sometimes after trauma, sometimes seemingly spontaneously. Treatment has been rather disappointing. Furthermore, RSTS patients run a higher risk of contracting cancer. A similar increase in cancer has been found in mice haploinsufficient for $C B P{ }^{22}$ A firm check-up scheme seems unneeded, but specific attention for the first symptoms that can indicate a tumor will allow early recognition of developing malignancies and thus increase the chances of successful intervention. Recently, a health watch program specifically for persons with RSTS has been developed, ${ }^{15}$ which deals with the above problems in much more detail.

The delayed motor and cognitive development in RSTS needs continuously attention. Almost all patients will be best stimulated if they will attend special schools for children with learning disabilities. The children are in general friendly, happy, and easy going. ${ }^{23}$ Nevertheless, $25 \%$ of the parents report behavioral problems often characterized by short attention span, stubbornness, lack of persistence, claiming behavior, and sudden mood changes. It becomes increasingly clear that in early adulthood behavior can change, leading to uncertain behavior and sometimes aggressiveness. The cause is unknown at present, although one may speculate that requirement throughout life for both functions of CBP (activation of CREB and chromatin remodeling) and possibly also $p 300$ plays a role here. ${ }^{24}$

\section{Conclusion}

RSTS may be regarded as one of the archetypical syndromes in clinical genetics. The developments around the entity have been evolved from careful clinical description to localizing and cloning of the causative genes. Functional studies that try to explain the various symptoms in RSTS form now the main part of research. Surely further work to explain the cause of the syndrome in the $45 \%$ of patients in whom no abnormality can be found is still needed. The study of a large group of RSTS patients for $p 300$ mutations and similar studies for mutations in cofactors for $C B P$ and p300 are needed. It will be useful for daily patient care if a tiling path micro-array for the chromosome regions of $C B P$ and $p 300$ will become available. 
Functional studies will have to focus on the HAT activity of $C B P$ and p300. How does the aberrant chromatin regulation and accessibility of DNA to transcription factors lead to the broad thumb-broad hallux phenotype? Which functions of $C B P$ and $p 300$ are important in later life, and do these influence the behavior of RSTS adults? This can be studied in transgenic mice haploinsufficient for $C B P / p 300$ but also needs long-term follow-up studies of behavior in RSTS patients. This is even more important as this might open ways to treat this behavior with phosphodiesterase- 4 inhibitors. ${ }^{25}$ It should be evaluated whether low $C B P$ levels are important in this respect: $C B P$ has also been found to be incorporated into nuclear inclusions formed by polyglutamine-containing proteins in cells from patients with Spinal and Bulbar Muscular Atrophy. ${ }^{26}$ Overexpression of $\mathrm{CBP}$ rescued the cells of these patients, indicating that the neurotoxicity may be caused by the lack of $C B P$. Again neuropsychological studies, if possible with long-term follow-up, are useful here.

Further work is needed for the keloid formation as well. Both the clinical characteristics as the molecular make-up (mRNA studies) will be useful. Lastly, the pathways through which insufficient functioning of CBP/p300 lead to an increased cancer risk can allow us to gain further insight in tumorigenesis.

Indeed, Sir James Paget was right when he made this statement in 1882, about the studies of rare diseases, like RSTS: 'We ought not to set them aside with idle thoughts or idle words about 'curiosities' or 'chances'. Not one of them is without meaning; not one that might not become the beginning of excellent knowledge'. ${ }^{27}$

\section{Parent support groups}

Brazilian support group (http://www.artsbrasil.org.br) Canadian support group (http://www.rtscanada.org) Danish support group (http://www.rubinstein-taybi.dk) Dutch support group (http://www.rtsyndroom.nl) French support group (http://www.afsrt.com) German support group (http://rts.freeservers.com/rts.html) Spanish support group (http://www.rubinsteintaybi.org) UK support group (http://www.rtsuk.org) US support group (http://www.rubinstein-taybi.org)

\section{References}

1 Rubinstein $\mathrm{JH}$, Taybi $\mathrm{H}$ : Broad thumbs and toes and facial abnormalities. Am J Dis Child 1963; 105: 588-608.

2 Hennekam RCM, Stevens CA, Van de Kamp JJ: Etiology and recurrence risk in Rubinstein-Taybi syndrome. Am J Med Genet Suppl 1990; 6: 56-64.

3 Gorlin RJ, Cohen Jr MM, Hennekam RCM: Syndromes of the Head and Neck, 4th Ed. New York: Oxford Medical Press, 2001.

4 Hennekam RCM, Van Doorne JM: Oral aspects of RubinsteinTaybi syndrome. Am J Med Genet Suppl 1990; 6: 42-47.

5 Stevens CA, Hennekam RCM, Blackburn BL: Growth in the Rubinstein-Taybi syndrome. Am J Med Genet Suppl 1990; 6: 51-55.
6 Van Genderen MM, Kinds GF, Riemslag FC, Hennekam RCM: Ocular features in Rubinstein-Taybi syndrome: investigation of 24 patients and review of the literature. Br J Ophthalmol 2000; 84: 1177-1184.

7 Goodfellow A, Emmerson RW, Calvert HT: Rubinstein-Taybi syndrome and spontaneous keloids. Clin Exp Dermatol 1980; 5: 369-370.

8 Hennekam RCM, Baselier JCA, Beyaert E et al: Psychological and speech studies in Rubinstein-Taybi syndrome. Am J Ment Retard 1992; 96: 645-660.

9 Miller RW, Rubinstein JH: Tumors in Rubinstein-Taybi syndrome. Am J Med Genet 1995; 56: 112-115.

10 Imaizumi K, Kuroki Y: Rubinstein-Taybi syndrome with de novo reciprocal translocation $\mathrm{t}(2 ; 16)(\mathrm{p} 13.3 ; \mathrm{p} 13.3)$. Am J Med Genet 1991; 38: 636-639.

11 Tommerup N, van der Hagen CB, Heiberg A: Tentative assignment of a locus for Rubinstein-Taybi syndrome to $16 \mathrm{p} 13.3$ by a de novo reciprocal translocation, $\mathrm{t}(7 ; 16)(\mathrm{q} 34 ; \mathrm{p} 13.3)$. Am J Med Genet 1992; 44: 237-241.

12 Lacombe D, Saura R, Taine L, Battin J: Confirmation of assignment of a locus for Rubinstein-Taybi syndrome gene to $16 \mathrm{p} 13.3$. Am J Med Genet 1992; 44: 126-128.

13 Breuning MH, Dauwerse JG, Fugazza G et al: Rubinstein-Taybi syndrome caused by submicroscopic deletions within $16 \mathrm{p} 13.3$. Am J Hum Genet 1993; 52: 249-254.

14 Hennekam RCM, Tilanus M, Hamel BC et al: Deletion at chromosome $16 \mathrm{p} 13.3$ as a cause of Rubinstein-Taybi syndrome: clinical aspects. Am J Hum Genet 1993; 52: 255-262.

15 Hennekam RCM: The Rubinstein-Taybi syndrome; in Cassidy SB, Allanson JA (eds):: Management of Genetic Syndromes. Hoboken, New Jersey: Wiley, 2005, pp 479-487.

16 Kalkhoven E, Roelfsema JH, Teunissen $\mathrm{H}$ et al: Loss of CBP acetyltransferase activity by PHD finger mutations in Rubinstein-Taybi syndrome. Hum Molec Genet 2003; 12: $441-450$.

17 Coupry I, Roudaut C, Stef M et al: Molecular analysis of the CBP gene in 60 patients with Rubinstein-Taybi syndrome. J Med Genet 2002; 39: 415-421.

18 Roelfsema JH, White SJ, Ariyurek Y et al: Genetic heterogeneity in Rubinstein-Taybi syndrome: mutations in both the CBP and EP300 genes cause disease. Am J Hum Genet 2005; 76: $572-580$.

19 Arany Z, Sellers WR, Livingston DM, Eckner R: E1A-associated p300 and CREB-associated CBP belong to a conserved family of coactivators. Cell 1994; 77: 799-800.

20 Bannister AJ, Kouzarides T: The CBP co-activator is a histone acetyltransferase. Nature 1996; 384: 641-643.

21 Yamamoto T, Kurosawa K, Masuno $\mathrm{M}$ et al: Congenital anomaly of cervical vertebrae is a major complication of Rubinstein-Taybi syndrome. Am J Med Genet 2005; 135A: 130-133.

22 Kung AL, Rebel VI, Bronson RT et al: Gene dose-dependent control of hematopoiesis and hematologic tumor suppression by CBP. Genes Dev 2000; 14: 272-277.

23 Hennekam RCM, Baselier JCA, Beyaert E et al: Psychological and speech studies in Rubinstein-Taybi syndrome. Am J Ment Retard 1992; 96: 645-660.

24 Alarcon JM, Malleret G, Touzani K et al: Chromatin acetylation, memory, and LTP are impaired in $\mathrm{CBP}+/-$ mice: a model for the cognitive deficit in Rubinstein-Taybi syndrome and its amelioration. Neuron 2004; 42: 947-959.

25 Bourtchouladze R, Lidge R, Catapano R et al: A mouse model of Rubinstein-Taybi syndrome: defective long-term memory is ameliorated by inhibitors of phosphodiesterase 4. Proc Nat Acad Sci 2003; 100: 10518-10522.

26 McCampbell A, Taylor JP, Taye AA et al: CREB-binding protein sequestration by expanded polyglutamine. Hum Molec Genet 2000; 9: 2197-2202.

27 Paget J: The Bradshawe lecture: some rare and new diseases. Lancet 1882; 2: 1017-1021. 